\title{
Vigilância Epidemiológica das Doenças Ocupacionais: Algumas Idéias.
}

\section{Ricardo Cordeiro*}

Quando se pensa em vigilância epidemiológica das doenças ocupacionais em nosso meio as primeiras, e talvez as mais importantes, questões que nos vêm à mente são o subdiagnóstico das doenças profissionais e o não reconhecimento de um grande número de doenças como parcialmente relacionadas ou agravadas por más condições de trabalho. Só para ilustrar sua dimensão, é interessante notar que, em relação a países do primeiro mundo tais como a Finlândia, a Itália e os Estados Unidos, a incidência registrada de doenças ocupacionais no estado de São Paulo na década de 80 e início dos anos 90 é cerca de 10 vezes menor.

Do ponto de vista clínico, o subdiagnóstico implica em um não reconhecimento de uma doença, impossibilitando a tomada de medidas terapêuticas. Além disso, impede o trabalhador de ter o reconhecimento jurídico/legal de sua condição, o que impossibilita a percepção dos"benefícios" a que faz jus. Entretanto, a maior implicação do subdiagnóstico não se dá na esfera da clínica, mas sim no âmbito de epidemiologia. Isto porque ele dificulta sobremaneira a ampliação do conhecimento da dinâmica de distribuição das doenças profissionais, dificultando o dimensionamento de sua magnitude e o seu controle, o que conseqüentemente vai dificultar a adoção de medidas de controle endereçada à população exposta e medidas mais gerais de prevenção. É importante salientar que a doença profissional é uma ocorrência intrinsecamente epidêmica. Raramente ocorre isoladamente. É antropogênica e evitável.

Sob esse aspecto, existem algumas perguntas elementares às quais infelizmente ainda não somos capazes de ao menos começar a responder. Há duas

\footnotetext{
* Prof. Dr. do Departamento de Saúde Pública da Faculdade de Medicina de Botucatu/SP.
} 
décadas se sabe que as três principais causas de morte em adultos no estado de São Paulo são: doenças cardiovasculares, neoplasias e as chamadas causas externas. Pois quanto dos que morreram por causas cardiovasculares tiveram seu quadro originado ou agravado por determinantes ligados ao trabalho? Quanto dos que morreram por neoplasias tiveram seu quadro desencadeado por exposições a agente cancerígenos? Quantos dos acidentes que implicaram em óbitos foram acidentes de trabalho, típicos ou não?

Por tudo, penso que a discussão da vigilância epidemiológica em doenças ocupacionais começa em nosso meio forçosamente pelo equacionamento do problema do seu subdiagnóstico.

É claro que a reversão do subdiagnóstico das doenças ocupacionais não é tarefa exclusiva da epidemiologia. Muito menos a melhoria da situação de saúde da população trabalhadora. A epidemiologia, no entanto, tem sim uma pequena contribuição a dar. Entendo-a como um método capacitado a estudar e compreender as relações que se estabelecem entre fenômenos do processo saúde/doença ocorrendo na sociedade e seu conjunto de determinantes sociais e biológicos. Neste sentido, pode fornecer um conjunto de informações valioso para os setores populares "negociarem" socialmente mudanças efetivas no sentido da promoção da saúde dos trabalhadores.

Assim, gostaria de aproveitar a oportunidade que a organização deste encontro me deu para colocar em discussão três idéias.

A primeira delas diz respeito às Comunicações de Acidentes do Trabalho. Existem algumas experiências bem sucedidas de utilização da CAT como fonte de informação para vigilância epidemiológica, a maioria delas utilizando-se de softwares para o gerenciamento das informações colhidas. Estas experiências implicaram em um avanço no conhecimento do perfil de morbidade ocupacional da população trabalhadora segurada em diversas regiões do estado e do país.

Entretanto, a grande limitação do trabalho com a CAT é a própria CAT . Esta é um documento administrativo do INSS, compartilhado hoje pelo SUS. circunstancialmente gera informações úteis, do tipo "é grande o número de acidentes com máquinas na indústria metalúrgica", ou "é grande o numero de acidentes devido a quedas na construção civil", mas não avança muito além disso. Acredito que hoje já estejam maduras as condições para o desenvolvimento e a implantação de um documento alternativo à CAT como fonte de informação epidemiológica. Esta tarefa, bastante grande, envolve trabalho em 3 áreas.

a) $\mathrm{O}$ desenvolvimento do instrumento propriamente dito, bem como o software necessário para o generiamento das informações geradas por ele.

b) O trabalho de educação e convencimento dos profissionais de saúde, desde os cursos de graduação, sobre a necessidade e a importância do documento. 
c) E por fim o trabalho na âmbito legal para tornar compulsória a notificação das doenças profissionais e dos acidentes de trabalho através deste documento.

A segunda idéia diz respeito aos critérios diagnósticos utilizados pela medicina do trabalho. A toxicologia e a medicina do trabalho mais ortodoxa estabelecem que o diagnóstico das intoxicações profissionais deva ser feito com base em critérios exclusivamente clínicos, isto é, através da evidência de sinais da doença no indivíduo. Tal rigor seria louvável se não implicasse em uma brutal subnotificação destas doenças em nosso meio. Em oposição ao critério clínico de diagnóstico, sugiro uma abordagem epidemiológica, baseada no conceito de risco relativo, para definir o limiar diagnóstico das intoxicações profissionais. Assim, pelo menos para as intoxicações profissionais mais prevalentes, devem ser legalmente definidos pontos de corte em seus indicadores biológicos de interesse, valores a partir dos quais começa a ser significativo o aparecimento de manifestação e complicações da doença em questão em uma dada população exposta. Desta maneira, o diagnóstico passaria a ser feito em um trabalhador quando este apresentasse indicadores de exposição ao xenobiótico, estes facilmente mensuráveis, em níveis a partir dos quais começa a aumentar o risco de aparecerem manifestações da doença, independentemente de documentação fisiopatalógica individual.

Tal abordagem diagnóstica não é novidade no campo das doenças crônicas não ocupacionais, tratando-se de uma questão política a sua utilização como prática corrente na saúde ocupacional.

Por fim, a terceira idéia diz respeito mais especificamente à produção científica na área. Existem algumas questões na área Saúde \& Trabalho cuja resolução é emergencial. Algumas delas diretamente ligas à vigilância epidemiológica, outras nem tanto. Estas questões só podem ser equacionadas através de pesquisa. Uma delas, para exemplificar, diz respeito aos valores dos limites de tolerância biológica oficialmente estabelecidos pelo Anexo II da Norma Regulamentadora No7 do Ministério do Trabalho, em 1983. Estes valores foram, em sua maioria,estabelecidos na Europa e nos Estados Unidos na década de 70, através de critérios de seriedade muitas vezes duvidosa, para serem aplicados a populações trabalhadoras locais. Foram importados mecanicamente no início dos anos 80 , sem nenhum processo de validação nacional. E hoje estão em sua maioria ultrapassados segundo o conhecimento atualmente acumulado. Os limites de tolerância biológica utilizados para os indicadores biológicos de interesse no acompanhamento da intoxicação profissional pelo chumbo são um exemplo paradigmático desta questão. O quanto estão superdimensionados estes limites e como devem ser redimensionados são objetos de estudos epidemiológicos de grande relevância para a saúde dos trabalhadores.

Este e outros problemas justificam a necessidade de estruturas fortes de pesquisa para seu equacionamento. 
Finalmente, como partir das propostas para as ações? Evidentemente não tenho esta resposta, mas gostaria de comentar uma intuição minha.

O desenvolvimento das idéias e ações anteriormente esboçadas encontra nos Programas de Saúde do Trabalhador (PSTs) um ambiente privilegiado e estratégico. Acredito que, apesar de todas as flutuações conjunturais por que passaram e passam ainda, o inovador na área Saúde \& Trabalho nos últimos 10 anos é a experiência dos PSTs levadas a cabo no estado de São Paulo, bem como em outros estados, como Bahia, Espírito Santo, Minas Gerais e Rio Grande do Sul.

É interessante notar que em São Paulo existe uma estreita correlação entre o vigor da experiência dos PSTs e a incidência registrada das doenças profissionais. Esta tem uma curva ascendente entre 85 e 87, momento de florescimento e ascensão dos PSTs no estado. Passa por um descenso entre 88 e 89 , justamente à época do retrocesso dos PSTs, parcialmente decorrente da desastrosa gestão Pinotti. Retomando depois o crescimento no início dos anos 90, período que coincide com a criação dos Centros de Referência em Saúde do Trabalhador pela prefeitura da capital.

O que confere ao PST a potencialidade de sediar e desenvolver essas ações é o agrupamento de algumas características, tais como; organizar-se fora do âmbito das empresas; contar com equipes técnicas efetivamente posicionadas a favor dos interesses populares e contar, ainda que de modo heterrogêneo e incipiente, com apoio sindical e retaguarda universitária. Em essência, trata-se de consolidar o PST, não só como um prestador de serviços de saúde e um agente interventor em ambientes de trabalho, mas também como um produtor de conhecimento de excelência . 